\title{
conf-9411137- -4 \\ Adventures in Supercomputing: An Innovative Program for High School Teachers
}

\author{
C. Edward Oliver \\ H. Richard Hicks \\ Barbara G. Summers \\ Computing, Networking, Informatics and Education \\ Oak Ridge National Laboratory* \\ P. O. Box 2008 \\ Oak Ridge, TN 37831-6486
}

David G. Staten

Wartburg Central High School

P. O. Box 303

Wartburg, TN 37887

PECEVED

MAN 05 Pes

03 TI

To be presented at the Frontiers in Education Conference, San Jose, CA, November 3 -6, 1994; to be published in the Proceedings.

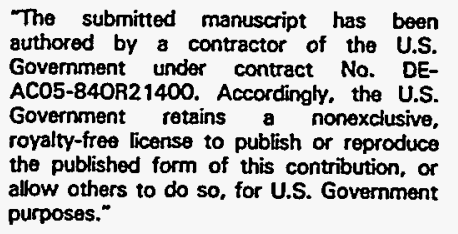

*Managed by Martin Marietta Energy Systems, Inc. under contract DE-AC05-84OR21400 with the U.S. Department of Energy

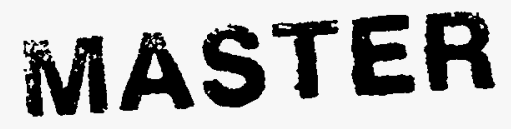

DISTRIBUTION OF THIS BOCUMENT IS UALIMITED 


\section{Adventures in Supercomputing: An Innovative Program for High School Teachers}

\author{
C. Edward Oliver \\ H. Richard Hicks \\ Barbara G. Summers \\ Oak Ridge National Laboratory*
}

\author{
David G. Staten \\ Wartburg Central High School
}

\section{INTRODUCTION}

Within the realm of education, seldom does an innovative program become available with the potential to change an educator's teaching methodology. Adventures in Supercomputing (AiS), sponsored by the U.S. Department of Energy (DOE), is such a program. It is a program for high school teachers that changes the teacher paradigm from a teacher-directed approach of teaching to a student-centered approach. "A student-centered classroom offers better opportunities for development of internal motivation, planning skills, goal setting and perseverance than does the traditional teacher-directed mode" [1].

Not only is the process of teaching changed, but the crosscurricula integration within the AiS materials is remarkable. Written from a teacher's perspective, this paper will describe the AiS program and its effects on teachers and students, primarily at Wartburg Central High School, in Wartburg, Tennessee. The AiS program in Tennessee is sponsored by Oak Ridge National Laboratory (ORNL).

\section{PROGRAM DESCRIPTION}

Adventures in Supercomputing was funded in 1992 as part of the U.S. Department of Energy's High-Performance Computing and Communications Program. The program presently involves 69 high schools and 5 middle schools in five states: Alabama, Colorado, Iowa, New Mexico, and Tennessee. Within these five states, over 160 teachers and more than 3,000 students are involved in the AiS program.

\section{Goal}

The primary goal of AiS is to capture and cultivate the interest of minority, female and disadvantaged students in science, mathematics and computing. To accomplish this

\footnotetext{
* Managed by Martin Marietta Energy Systems, Inc. under contract DE-AC05-84OR21400 with the U.S. Department of Energy.
}

goal, the computer literacy and scientific knowledge of the teachers of these students are improved through education, training, and curriculum materials.

\section{Summer Institute}

A faculty team consisting of at least two teachers from each of the participating schools attends an intensive Summer Institute for two weeks. During the Institute, the teachers are prepared to guide students in programming solutions to scientific problems. Teachers not only receive,curriculum materials for presenting introductory concepts in highperformance computing but also software applications with demonstrated success in the content areas, along with examples on the use of high-level tools in modeling scientific problems. The Institute consists of hands-on experience in several areas: FORTRAN and parallel programming techniques, UNIX system, Spyglass Transform (visualization software), Macintosh familiarization, ClarisWorks (an integrated software package), and Internet usage.

The teachers begin the Institute by unpacking Macintosh computers and connecting them to a local area network with Internet access. After they learn some Macintosh basics, they are ready to begin working with the AiS curriculum.

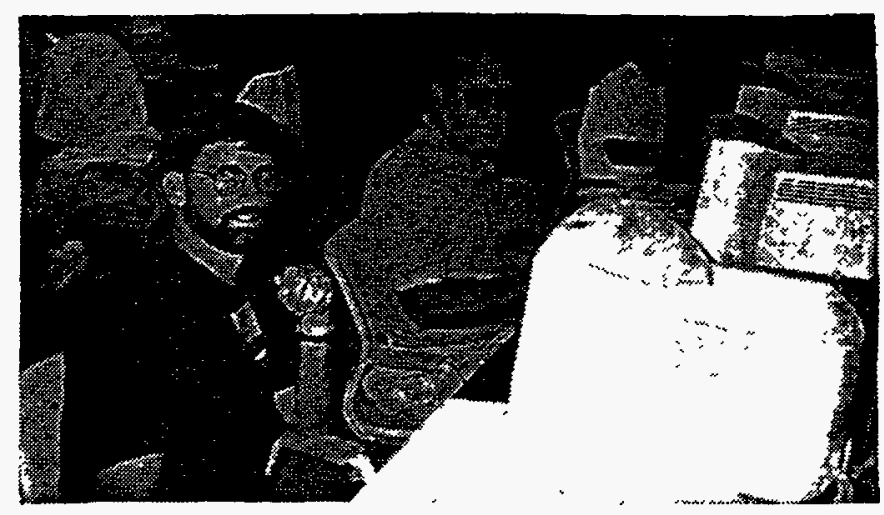

Teachers participating in the Summer Institute at ORNL 
Using skills learned during the Institute, the teacher teams complete mini-projects and present oral reports to fellow Institute members. Within the two weeks, the teachers acquire the skills necessary to begin a computational science course at their school.

The teachers understand the importance of the interconnection of computer networks in "a global research and development communication and information infrastructure" as they correspond through E-mail [2]. Email and Internet access allow them to collaborate with persons from around the world as they do research and carry out communication on the Internet.

nother essential element of the Institute is the development of curriculum materials specific to meet the needs of each school. After the teachers decide on a course outline, they prepare a time line for project development. This time line will enable them to keep the students on target as they begin to work on their projects.

With the curriculum materials provided by AiS and the course outline developed by the teaching team, the teachers are well prepared to guide their students in a year-long computational science project.

On two weekends during the school year following the Institute, Midcourse Workshops are held. These gatherings are intended to further enhance the communication among teachers within the state. During the workshops, teachers are given time to share successes and make suggestions. By sharing with each other both successes and failures, the overall AiS program is strengthened.

\section{Resources Provided}

The AiS students and teachers in Tennessee have access to an eight-processor nCUBE high-performance parallel processor computing system that is on loan to ORNL from nCUBE, Inc. for the AiS program. This nCUBE is attached to a Sun workstation ("Suncube") which provides the user environment and accounts for AiS students and teachers. Program participants access this system through 56-kilobitper-second Internet connections provided for each school. Students use the Suncube to carry out their computational programming and electronic mail.

DOE lends each school four Macintosh computers and an HP inkjet color printer. Each Macintosh is provided with the necessary software to help students complete computational science projects. This software includes visualization software and Internet exploration tools, such as Mosaic and TurboGopher.
Traditionally, even those schools fortunate enough to have technology resources usually have been donated obsolete technology in the form of cast-off equipment. The AiS program provides hardware, software, and network access that is as modern as that found in most universities and research centers.

\section{Experiments}

Although the AiS program itself is an experiment that is being closely monitored, we have conducted some experiments within AiS by introducing variations on the basic program in some schools. One school has been provided with a UNIX workstation and four X Terminals, to compare this environment to the Macintosh environment. Several schools have been loaned PowerBooks to provide both additional computers in the classroom and the capability for teachers and students to work from home.

\section{Grade level}

Initially, the program has been available to high schools. It has been observed that often the 9th and 10th graders have been the best AiS students. The 1994-95 school year will see the introduction of AiS materials, appropriately modified, into five middle schools, one in each AiS state. The intent is to expand AiS through the addition of middle schools that are feeders to current AiS high schools.

\section{A TEACHER'S PERSPECTIVE}

Wartburg Central High School is located in East Tennessee in the Cumberland Mountains. The school is in a rural setting with about 450 students in grades 9 through 12 . This area has one of the lowest per-capita incomes in Tennessee.

Our school applied for the AiS program during the 1991-92 school year. The school selection was made in the Spring of 1992, and Central High was chosen. We were very pleased to have been selected and viewed the participation in the program as a way to obtain computers for our school. Little did we realize the impact the AiS program would have, not only on us, but the entire school.

\section{Training Begins}

The excitement about the program began during the Summer Institute, where we received our first training. We were exposed to FORTRAN, UNTX, and visualization software, as well as various Internet access tools. Within the two-week session, we quickly saw the value of this advanced technology and realized the impact it would have on our students. 
We found ourselves getting excited about learning, and pushed ourselves to learn how to write FORTRAN programs to produce or analyze data. We also learned how to do research using the Internet to find information for our projects. Quickly, we learned to work as a team and were reminded of the value of cooperative learning. We would get so involved in our work that the instructors would have to remind us of breaks and meals. We dreaded the words "Turn off your computer!" We argued for more time to get our work done and to do more advanced projects than those required.

\section{New technology, renewed enthusiasm}

These technological tools that we were learning to use would also foster our "student's abilities, revolutionize the way they work and think, and give them new access to the world" [3]. The computer would become a tool to do research, solve mathematical problems, simulate and model problems and help students produce a finished product.

It became evident that our students would respond in the same way we did. It was clear that the traditional teacherdirected classroom would not be suitable for the AiS course in computational science.

\section{Curriculum}

Today supercomputers are powerful enough to simulate scientific experiments. Computational Science is about using computers to analyze scientific and engineering problems using high-performance computers in innovative ways, and it complements experimental and theoretical science. Computational techniques can be practical and useful when the experiments would be too expensive or unsafe, when experimental results would be difficult to analyze, or when the experiment is too large or too small, too slow or too fast. The scientific world is relying increasingly on computational scientists to construct models or simulate experiments. The AiS curriculum brings computational science to the classroom in the context of high school supercomputing science or mathematics classes. Because the curriculum is project-driven, the students learn the importance of computational science as they begin work on projects.

As the projects are developed, the students learn the many skills that the teachers learned during the Institute. The knowledge of FORTRAN helps the students incorporate formulas into a program and execute it using different values for the variables. After producing data, they analyze and represent the data. To do this, they must understand and be able to manipulate the visualization software. They produce a final report and usually do an in-class presentation for their classmates.

True integration of curricula is achieved as students use math, science, and English skills to help them complete their projects. After the students understand the procedure of projects, they do research on various topics of interest to determine an area in which to concentrate. The student and fellow team members must narrow the usually broad topic into something more concise. Teachers and students seek out mentors to work with the students on their projects. The curriculum is enhanced as the many educators and professional scientists and researchers become involved with the students.

One of the most important skills the students must learn is the management of information. Their ability to organize and relate the information is essential. By integrating the curriculum, many skills of the students are used. The students see the relationship between math, science and computing. They understand the need to interpret data and analyze the data to thoroughly understand it. The need for language skills is demonstrated as the student shares the project, both in written and oral presentations.

The curriculum requires each student to participate in a project. In late spring these projects are displayed in a statewide Exposition. The top projects from each state compete in a national AiS Exposition. This year's national winner was a talented sophomore team of female students from Murfreesboro, Tennessee. Their project was "Atomic Radii: Speculate or Calculate."

\section{$\underline{\text { New Methods }}$}

It is important to integrate the computer into the AiS computational science curriculum and not be guilty of teaching only computer techniques or computer science.

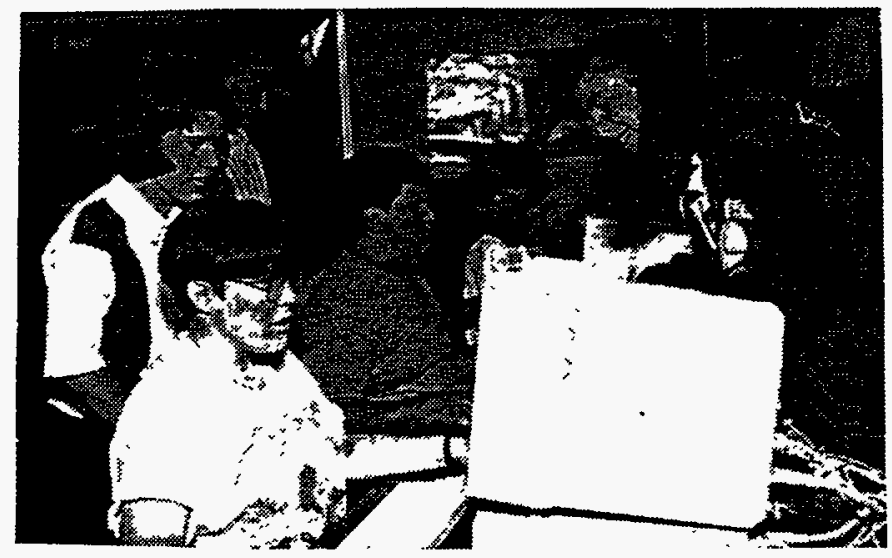

Students At Wartburg, Tennessee, working on computers loaned by DOE for Adventrues in Supercomputing Program 
As other teachers have experienced, learning the computer is not the primary objective. "The primary objective is to learn ideas from math, science, language arts, social studies, or some other content area" [4]. We began to think of the computers as tools to aid us in teaching science.

Instead of the traditional lecture followed by questions, we had to learn to allow the students to explore areas of interest to them. They learned to examine the Internet and became familiar with accessing information. They were able to post questions to bulletin boards and sometimes within hours receive answers. This is not surprising when we realize that some 40,000 messages are posted daily on bulletin boards. [5]. Students became more self confident as they searched for answers and information. No longer did they depend on the teachers to answer every question. Students learned to use Internet tools such as Gopher, Archie, Mosaic and Fetch as they looked for information. Their interaction with the Internet, a new form of communication for them, certainly began changing the way they thought. Writing, not just oral communication, became critical as they used their English skills to post messages or to write to people using E-mail.

The interaction between teachers and the students helped develop the students' independence. We realized that we did not need in-depth knowledge on each of the projects. We did, however, need to offer direction and suggestions to the students. We also found mentors who had expertise in the various project areas. Our classroom changed from teacher-centered to student-centered environment. The instruction between teacher and student became studentcentered and more personal [6]. No longer were we in a situation where one person talks and then students take home assignments that sometimes are confusing and frustrating.

\section{IMPACT ON THE STUDENTS}

We were excited about starting the computational science class and sharing our new knowledge and technology with the students. Coming from a very rural community where the socioeconomic level is low, the majority of the students did not have computers at home. This program gave the students a chance to use the latest technology as a learning tool.

As we expected, the students were enthusiastic about getting to use a computer in the classroom. This enthusiasm seemed to grow as time passed. Students were coming to school early and voluntarily staying late to learn more. It is delightful to have students so eager to learn and discover new territory. "When educators allow students to interact with technologies in meaningful ways for significant periods of time, the growth that follows will encourage educators to try new things" [3].

\section{Student Projects}

The students chose a research area of interest for their computational project. By allowing the students to choose, they were working in an area they wanted to investigate. "Students need to be involved in their own learning and the decisions about their learning" [4]. While continuously learning more tools to use, the students developed their projects. Our role changed from teaching to guiding the students in their research. The students soon reached a level where their knowledge of their chosen subject was well above ours.

\section{Project titles for the 1993-94 school year:}

"The Greenhouse Effect"

"Acoustics in Concert Halls"

"Metabolic Rates of Mammals"

"Depletion of the Ozone Layer"

"Projected Crop Yield in Tennessee"

"Filtering Background Noise in Hearing Aids"

"Stability and Feedback in Magnetic Levitation"

"Comparison and Analysis of Superconducting Material Data"

"Determining Transport Parameters from Laboratory and Field Tracers"

\section{$\underline{\text { Mentors }}$}

We began trying to find people who were knowledgeable in the chosen areas to serve as mentors for the students. The students corresponded with scientists and professors from Oak Ridge National Laboratory and the University of Tennessee. These mentors provided up-to-date information and knowledge for the students to use in their projects. Working with the scientists and professors gave the students pride in their project. The students acquired information and data for their computations. They began visualizing and drawing conclusions from these data for their projects.

\section{PROJECTS}

The AiS program at Central High School has been a success. The enthusiasm for the subject continues to increase. The enrollment for the course has almost doubled over the past two years. The projects the students have developed in two years have been impressive. The project topics included Structural Advantages of Composite Materials, Recombinant DNA, Magnetic Levitation, and Analyzing Hearing Aid Filters. Last year a sophomore, Lacy Phillips, completed a project that approximated the 
potential crop growth in Tennessee. This project contained over 500,000 values for soil type and ground coverage. The FORTRAN coding ran in parallel, using all eight processors on the nCUBE supercomputer at ORNL. In just two years, the AiS program at Wartburg Central has progressed to the point of high school students doing scientific research, collecting large amounts of data, and writing programs that will run on multiple processors.

\section{Career opportunities}

Not only has the class been a spark to the students at school, but it has changed the direction of several students. One senior in the first year of AiS decided to study material science. His project was "Composite Materials: Advantages in Aerospace Engineering." His mentor is a research engineer in the Metals and Ceramics Division at ORNL. Because of the mentor's interest in the student and the interaction between the two, the student has a summer internship at ORNL with the possibility of employment when he earns his college degree.

Of the ten seniors who have completed the AiS course, more than half have enrolled in college to enter fields dealing with computers. Two of these students made this career decision because of their involvement in AiS. Half of the AiS students going to college were in the target group of AiS.

Not only Seniors have benefited from the program. Three underclassmen are working this summer at ORNL in various scientific programs. Another student, who was too young to work this year, has been offered a position next summer in the Environmental Sciences Division.

"The greatest service that technology can render to education lies in communication and curriculum" [7]. By using the technology now available to them, the students are able to create. No longer are they confined by a set of traditional limits. During the AiS class, students are attending a school without walls as they access the world. They are able to transcend the limitations of time and space and travel without leaving the room. What doors are open to the students of Wartburg!

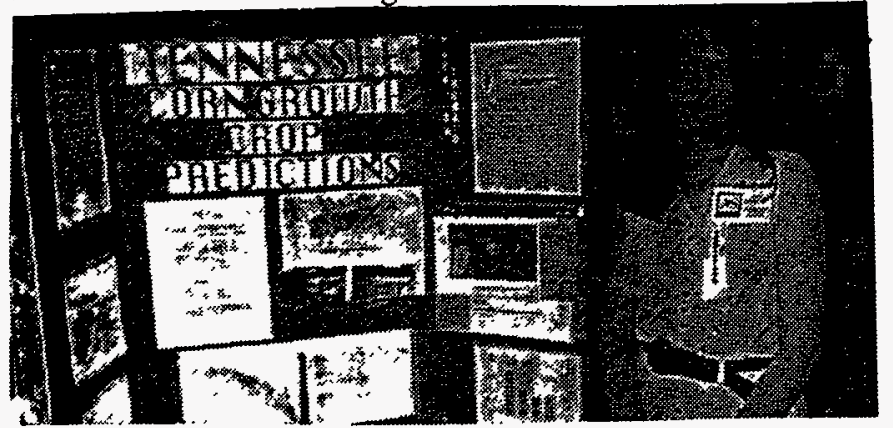

Lacy Phillips with project display poster at AiS Exposition

\section{REFERENCES}

[1] Smith, Katy. "Becoming the 'Guide on the Side'." Educational Leadership. Oct. 93: 35-37.

[2] Maslen, Geoffrey. Society Oversees the Global Growth on the Internet. The Chronicle of Higher Education. June 94: A20-A21.

[3] Peck, Kyle and Dorricott, Denise. "Why Use Technology?" Educational Leadership. Apr. 94: 11-14.

[4] Muir, Mike. "Putting Computer Projects at the Heart of the Curriculum." Educational Leadership. Apr. 94: 30-32.

[5] Steinberg, Stephen. "Travels on the Net." Technology Review. July 94: 20-31.

[6] Thomas, Donald W. "Technology's Next Phase is Ready to Fly: Are WE?" Education Digest. May 94: 13-16.

[7] Wilson, John T. and Chalmers-Neubauer, Irene. A Comparison of Teacher Roles in Three Exemplary HandsOn Elementary Science Programs. Science Education. 74(1): $69-85$

\section{Edward Oliver}

Dr. C. Edward Oliver received his Ph.D. in Mathematics in 1969 from the University of Alabama. He is currently an Associate Director of Oak Ridge National Laboratory.

\section{H. Richard Hicks}

Dr. H. Richard Hicks received his Ph.D. in Physics in 1971 from the University of Illinois. Hicks is in the Office of Laboratory Computing at Oak Ridge National Laboratory.

\section{Barbara G. Summers}

Barbara G. Summers received her Masters in Curriculum Development in 1980 from Tennessee Technology University. She taught math, science and computer programming for 24 years in Wartburg, Tennessee. She is presently coordinating the Adventures in Supercomputing program for Tennessee through the office of Science Education and External Relations at Oak Ridge National Laboratory.

\section{David G. Staten}

David G. Staten received his Masters in Mathematics from the University of Tennessee. He teaches math and computational science in Wartburg, Tennessee. 


\section{DISCLAIMER}

This report was prepared as an account of work sponsored by an agency of the United States Government. Neither the United States Government nor any agency thereof, nor any of their employees, makes any warranty, express or implied, or assumes any legal liability or responsibility for the accuracy, completeness, or usefulness of any information, apparatus, product, or process disclosed, or represents that its use would not infringe privately owned rights. Reference herein to any specific commercial product, process, or service by trade name, trademark, manufac: turer, or otherwise does not necessarily constitute or imply its endorsement, recommendation, or favoring by the United States Government or any agency thereof. The views and opinions of authors expressed herein do not necessarily state or reflect those of the United States Government or any agency thereof. 